\title{
A Data Filter for Identifying Steady-State Operating Points in Engine Flight Data for Condition Monitoring Applications
}

Donald L. Simon and Jonathan S. Litt

Glenn Research Center, Cleveland, Ohio 


\section{NASA STI Program . . . in Profile}

Since its founding, NASA has been dedicated to the advancement of aeronautics and space science. The NASA Scientific and Technical Information (STI) program plays a key part in helping NASA maintain this important role.

The NASA STI Program operates under the auspices of the Agency Chief Information Officer. It collects, organizes, provides for archiving, and disseminates NASA's STI. The NASA STI program provides access to the NASA Aeronautics and Space Database and its public interface, the NASA Technical Reports Server, thus providing one of the largest collections of aeronautical and space science STI in the world. Results are published in both non-NASA channels and by NASA in the NASA STI Report Series, which includes the following report types:

- TECHNICAL PUBLICATION. Reports of completed research or a major significant phase of research that present the results of NASA programs and include extensive data or theoretical analysis. Includes compilations of significant scientific and technical data and information deemed to be of continuing reference value. NASA counterpart of peer-reviewed formal professional papers but has less stringent limitations on manuscript length and extent of graphic presentations.

- TECHNICAL MEMORANDUM. Scientific and technical findings that are preliminary or of specialized interest, e.g., quick release reports, working papers, and bibliographies that contain minimal annotation. Does not contain extensive analysis.

- CONTRACTOR REPORT. Scientific and technical findings by NASA-sponsored contractors and grantees.
- CONFERENCE PUBLICATION. Collected papers from scientific and technical conferences, symposia, seminars, or other meetings sponsored or cosponsored by NASA.

- SPECIAL PUBLICATION. Scientific, technical, or historical information from NASA programs, projects, and missions, often concerned with subjects having substantial public interest.

- TECHNICAL TRANSLATION. Englishlanguage translations of foreign scientific and technical material pertinent to NASA's mission.

Specialized services also include creating custom thesauri, building customized databases, organizing and publishing research results.

For more information about the NASA STI program, see the following:

- Access the NASA STI program home page at http://www.sti.nasa.gov

- E-mail your question via the Internet to help@ sti.nasa.gov

- Fax your question to the NASA STI Help Desk at 443-757-5803

- Telephone the NASA STI Help Desk at 443-757-5802

- Write to: NASA Center for AeroSpace Information (CASI) 7115 Standard Drive Hanover, MD 21076-1320 


\section{A Data Filter for Identifying Steady-State Operating Points in Engine Flight Data for Condition Monitoring Applications}

Donald L. Simon and Jonathan S. Litt

Glenn Research Center, Cleveland, Ohio

Prepared for the

Turbo Expo 2010

sponsored by the American Society of Mechanical Engineers (ASME)

Glasgow, Scotland, United Kingdom, June 14-18, 2010

National Aeronautics and

Space Administration

Glenn Research Center

Cleveland, Ohio 44135 


\section{Acknowledgments}

The authors graciously acknowledge the organizations that contributed to this effort including the United States Army Aviation and Missile Research Development Engineering Center, Aviation Engineering Directorate; the United States Army Research Laboratory, Vehicle Technology Directorate; and the NASA Aviation Safety Program, Integrated Vehicle Health Management Project.

Trade names and trademarks are used in this report for identification only. Their usage does not constitute an official endorsement, either expressed or implied, by the National Aeronautics and Space Administration.

Level of Review: This material has been technically reviewed by technical management.

Available from

NASA Center for Aerospace Information 7115 Standard Drive

Hanover, MD 21076-1320
National Technical Information Service 5301 Shawnee Road Alexandria, VA 22312

Available electronically at http://gltrs.grc.nasa.gov 


\title{
A Data Filter for Identifying Steady-State Operating Points in Engine Flight Data for Condition Monitoring Applications
}

\author{
Donald L. Simon and Jonathan S. Litt \\ National Aeronautics and Space Administration \\ Glenn Research Center \\ Cleveland, Ohio 44135
}

\begin{abstract}
This paper presents an algorithm that automatically identifies and extracts steady-state engine operating points from engine flight data. It calculates the mean and standard deviation of select parameters contained in the incoming flight data stream. If the standard deviation of the data falls below defined constraints, the engine is assumed to be at a steadystate operating point, and the mean measurement data at that point are archived for subsequent condition monitoring purposes. The fundamental design of the steady-state data filter is completely generic and applicable for any dynamic system. Additional domain-specific logic constraints are applied to reduce data outliers and variance within the collected steady-state data. The filter is designed for on-line real-time processing of streaming data as opposed to postprocessing of the data in batch mode. Results of applying the steady-state data filter to recorded helicopter engine flight data are shown, demonstrating its utility for engine condition monitoring applications.
\end{abstract}

\section{Introduction}

Aircraft operators rely on engine condition monitoring programs to assist them in managing the health of their gas turbine engine assets. These functions, which are based on engine gas path measurement data collected at a small number of quasi-steady-state operating points each flight, are typically performed in off-board ground stations (Refs. 1 to 3 ). The quality of the steady-state measurement data directly impacts the quality and timeliness of the corresponding health assessments. For commercial transport aircraft, which follow a consistent flight profile including extended time at cruise operating points, data acquisition strategies are applied to collect engine data at relatively consistent points from flight to flight. However, for military or other aircraft that do not follow a regular flight profile, data acquisition at repeatable engine operating points each flight is not possible, or may be limited to takeoff data points only. Engines on these aircraft can experience a broad range of operating conditions during the course of a flight, including periods of transient and of quasi-steady-state operation. The steady-state data acquisition approach presented in this paper is applicable for all aircraft engines including those that exhibit relatively stable operating profiles and those that exhibit highly transient behavior. The approach is designed for real-time on-board implementation, but it can also be used for processing recorded data post-flight. In either application it will significantly compress the data into a reduced number of points reflecting engine performance. Such an approach is beneficial for situations where it is not practical to transmit full flight data sets off the aircraft, or to archive flight data for the entire lifetime of an engine.

This work was initiated under a previous effort conducted by the authors to develop a prototype technique to perform the real-time automated assessment of available power in helicopter turboshaft engines (Ref. 4). That effort included the development of a steady-state data filter designed to process actual helicopter engine Health and Usage Monitoring System (HUMS) data to extract steady-state operating points. The steady-state data were in turn utilized to trend engine operating performance over time. Although initially applied to helicopter engine data, this filter and the associated lessons learned have broad applicability to other aircraft gas turbine engine applications including fixed-wing military and commercial aircraft.

The remaining sections of this paper are organized as follows. First, the steady-state data filter architecture is presented and individual elements are discussed. Next, additional logic applied to limit analysis of data to that collected within a user-defined range of the engine operating envelope and to reduce data outliers is discussed. Several examples of the steady-state data extracted by the filter from helicopter engine flight data sets are given. These include examples of engines exhibiting nominal performance characteristics, as well as several anomalous performance examples. Following the example results, a discussion of practical considerations for applying the method is provided. Finally, conclusions are presented.

\section{Nomenclature}

$\begin{array}{ll}\text { KIAS } & \text { Indicated airspeed, knots } \\ \text { HUMS } & \text { Health and usage monitoring system } \\ \text { LPF } & \text { Low pass filter } \\ \mathrm{N} & \text { Number of samples in steady-state buffer } \\ \mathrm{Ng} & \text { Gas generator speed } \\ \mathrm{Np} & \text { Power turbine speed } \\ \mathrm{OAT} & \text { Outside air temperature } \\ \mathrm{SHP} & \text { Shaft horsepower } \\ \text { TGT } & \text { Turbine gas temperature } \\ T_{\text {minbuff }} & \text { Minimum steady-state buffer length } \\ T_{\text {thermmax }} & \text { Maximum temperature difference }\end{array}$




$\begin{array}{ll}y_{k} & \text { Parameter sample at current time step, } \mathrm{k} \\ \sigma & \text { Standard deviation } \\ \mu & \text { Mean } \\ \omega_{n} & \text { Low pass filter natural frequency } \\ \zeta & \text { Low pass filter damping ratio } \\ \tau_{\text {therm }} & \text { Thermal transient filter time constant } \\ k & \text { Time sample index (subscript) }\end{array}$

\section{Steady-State Data Filter Approach}

The steady-state data filter, which is coded in Matlab (The MathWorks, Inc.), is designed to perform the real-time identification and archiving of steady-state engine operating points from streaming flight data. The architecture of this filter is shown in Figure 1. The fundamental component of the architecture is the state transition logic, which determines the steady-state operating status of the engine. The state transition logic is predominantly generic, and can be applied to data collected from any dynamic system with minor modifications. The other components shown in Figure 1 are included to improve the quality and quantity of the identified steady-state operating points. The incoming flight data processed by the steady-state data filter consist of various sensed engine and aircraft parameters of interest, selected by the end user. Each incoming parameter stream, or channel, of the flight data first passes through a discrete low pass filter to reduce noise. Additional logic is applied to detect large thermal transients (thermal transient filter) and to ensure that data are only archived from desired regimes of the engine operating envelope (operating regime recognition logic). The low pass filtered data, the engine's thermal transient status, and the engine's operating regime status are passed into the state transition logic. Here the data are buffered into a window of data, and the mean and standard deviation of each parameter within the buffer window are calculated. The logic transitions between different states denoting transient or steady-state operation based upon whether standard deviation magnitude, persistency, and operating regime constraints are met. A vector of parameter means is archived for each identified steady-state operating point. The remainder of this section will discuss each element of the architecture in more detail.

\section{State Transition Logic}

The steady-state data filter is designed to facilitate on-line real-time processing of dynamic data (as opposed to postprocessing of the data in a batch mode). The key component of the filter is the state transition logic shown in Figure 2. Most of the state transition logic is completely generic. Domain-specific knowledge is only incorporated through a small number of operating regime conditional statements.

The state transition logic has three states it can transition between when processing incoming data. These three states are described below:

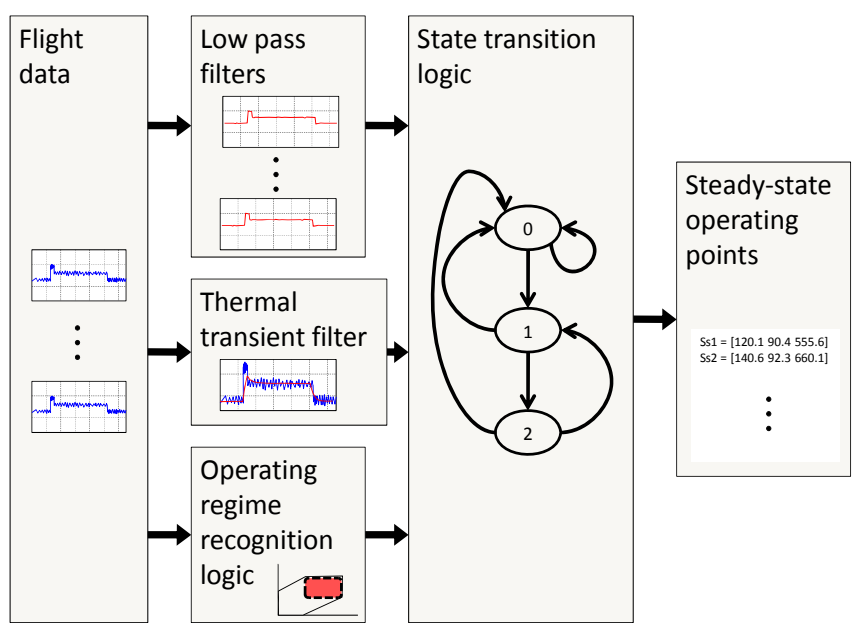

Figure 1.-Steady-state data filter architecture.

\section{State 0: Buffer initial window of data}

Within State 0 an initial window of data of a user specified length is buffered. The time length of this buffer is referred to as $T_{\text {minbuff. }}$ The underlying logic associated with State 0 is:

- The state transition logic enters State 0 upon startup and any resets.

- The logic remains in State 0 until a $T_{\text {minbuff }}$ window of data is buffered from the incoming data stream.

- Encountering any of the following conditions will result in the buffer being cleared (reset), and the state transition logic remaining in State 0 :

- Operating regime exceedance.

- Thermal transient exceedance.

- Data dropouts in the incoming data stream.

- Once a $T_{\text {minbuff }}$ window of data is buffered, the mean and standard deviation of the data contained within the window for each parameter are calculated. If the standard deviation of all parameters falls below user specified thresholds, the engine is considered to be at steady-state. The program will transition to:

- State 1 if the steady-state criteria are not met.

- State 2 if the steady-state criteria are met.

\section{State 1: Sliding Buffer Window of Non-Steady-State Data}

Within State 1, the state transition logic slides the buffer window of data forward in time when a new incoming data slice becomes available. This is achieved by appending the new data slice to the buffer and discarding the oldest data slice. This buffer will be of fixed length, specified by $T_{\text {minbuff }}$. The logic within State 1 does the following:

- Recursively calculates the mean and standard deviation for each parameter whenever an update to the buffer occurs. 


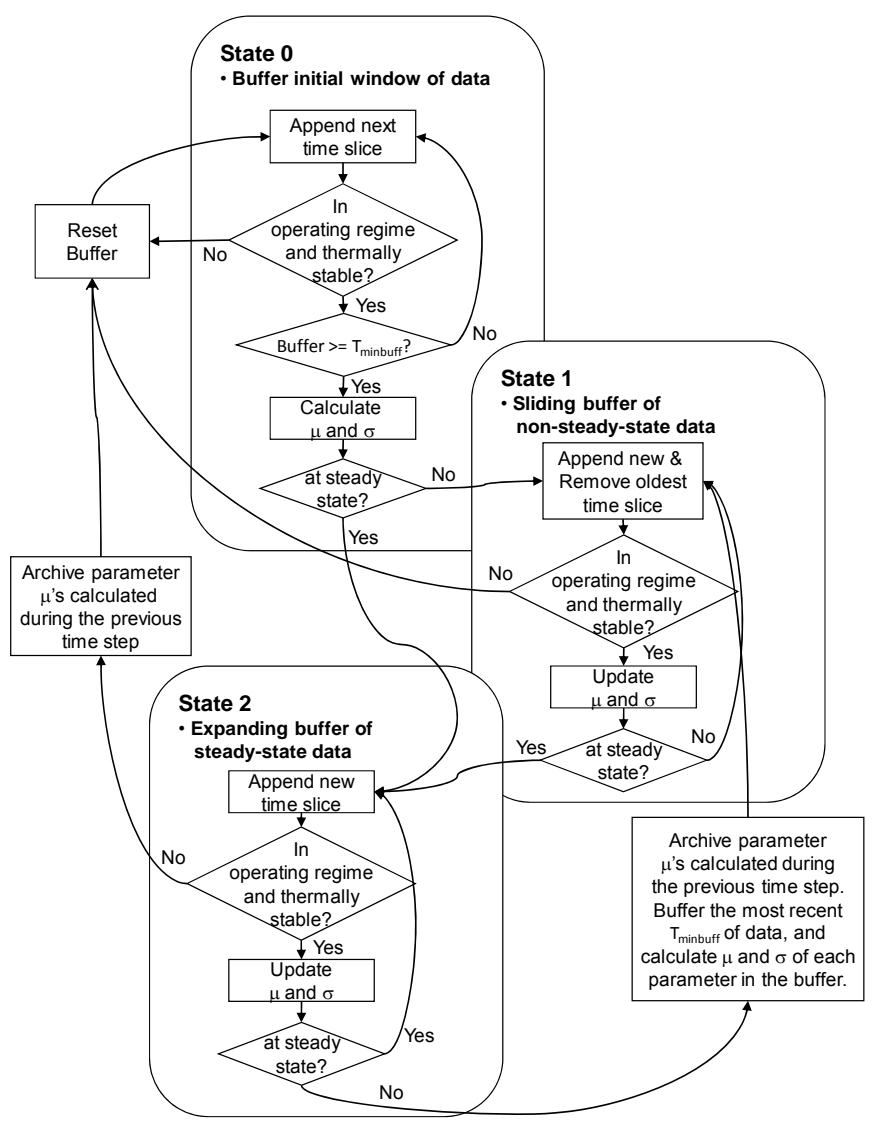

Figure 2.- Steady-state data filter state transition logic.

- Remains in State 1 while:

- The steady-state criteria are not met

and

- Operating regime exceedance, thermal transient exceedance, and data dropouts are not encountered.

- Triggers a transition to State 2 if the steady-state criteria are met.

- Triggers a transition to State 0 if operating regime exceedance, thermal transient exceedance, or data dropouts occur.

\section{State 2: Expanding Buffer Window of Steady-State \\ Data}

If all of the defined steady-state criteria are met, the state transition logic enters State 2. In State 2, the buffer is expanded by appending new incoming data as long as all steady-state criteria continue to be met. The logic associated with State 2 does the following:
- Appends new time slices of data to the existing steadystate data buffer.

- Recursively calculates the mean and standard deviation for each parameter in the buffer each time new data are added.

- If operating regime exceedance, thermal transient exceedance, or data dropouts are encountered, mean steady-state data that were calculated during the previous time step are archived, the buffer is reset, and the logic transitions to State 0 .

- If the standard deviation of any of the parameters exceeds its defined threshold, the engine is assumed to no longer be in steady-state. As a result, the logic associated with State 2 does the following:

- The mean parameter values that were calculated during the previous time step are archived.

- A new data buffer consisting of the most recent $T_{\text {minbuff }}$ window of data is created.

- The mean and standard deviation of each parameter within the new window are calculated.

- The logic transitions to State 1.

No limit is placed on the maximum size of the buffer window in State 2. In general, a larger buffer will require a larger transient to trigger a standard deviation threshold exceedance. However, this has not been found to have any noticeable effect on the quality of the archived mean steadystate data.

\section{Recursive Calculation of Mean and Standard Deviation}

To facilitate real-time implementation, the mean, $\mu$, and standard deviation, $\sigma$, of each parameter are calculated recursively. Whenever a new time slice of data is added to an existing data buffer, the standard deviation and mean for each incoming parameter are updated. Re-calculating the mean and standard deviation values each time step based upon all samples stored in the buffer (batch mode) would require considerable processing overhead. Therefore, recursive calculations for the mean and standard deviation are used. These equations only require the mean and standard deviation values from the previous time step, the most recent parameter sample, and in the case of the sliding window (State 1) the oldest parameter sample. There are a few issues that complicate this logic, namely:

- Parameters are not all sampled at a common frequency.

- Parameters that are sampled at a common frequency are not necessarily synchronized to sample at the same time.

- Synchronization discontinuities in the data sample rate and intermittent data dropouts occasionally occur.

The steady-state data filter includes logic to account for each of the issues listed above. 
Different recursive mean and standard deviation calculations are applied depending on which state the logic is in. These calculations are shown below:

1. New parameter appended, oldest parameter removed from buffer channel (sliding buffer-State 1)

$$
\mu_{k}=\mu_{k-1}+\frac{\left(y_{k}-y_{0}\right)}{N}
$$

$\sigma_{k}=\sqrt{\begin{array}{l}\sigma_{k-1}^{2} \cdots \\ +\frac{1}{(N-1)}\left[\left(y_{k}-\mu_{k-1}\right)\left(y_{k}-\mu_{k}\right)-\left(y_{0}-\mu_{k-1}\right)\left(y_{0}-\mu_{k}\right)\right]\end{array}}$

where

$N$ number of parameter samples in buffer channel

$k$ current time step

$y_{k} \quad$ parameter sample at current time step, $k$

$y_{0}$ oldest parameter sample, which is being removed from buffer

2. New parameter appended to existing buffer channel (expanding buffer-State 2)

$$
\begin{gathered}
\mu_{k}=\mu_{k-1}+\frac{y_{k}-\mu_{k-1}}{N} \\
\sigma_{k}=\sqrt{\frac{1}{N-1}\left((N-2) \sigma_{k-1}^{2}+\left(y_{k}-\mu_{k-1}\right)\left(y_{k}-\mu_{k}\right)\right)}
\end{gathered}
$$

Equations (1) to (4) can be derived from the approaches and formulas for the recursive calculation of mean, variance, and standard deviation in References 5 to 7.

\section{Low Pass Filters}

During initial development, the steady-state data filter was applied to a helicopter HUMS data set. At this time, an interesting observation was made when comparing the number of steady-state data points the filter identified in the two engines installed on the same aircraft. Although the two engines were operated in a very similar fashion, the steadystate data filter consistently identified more steady-state points in engine no. 2 than it did in engine no. 1. Upon closer observation it was discovered that the primary factor causing this discrepancy was the variance in engine sensor measurements, particularly the engine no. 1 torque sensor measurement. To address this issue, discrete second order low pass filters (LPFs) were added to pre-process the data contained in each incoming HUMS data channel. The formulation of the LPFs is given in Eq. (5) where $\omega_{n}$ is the natural frequency and $\zeta$ is the damping ratio of the filter. Although Eq. (5) is shown in continuous time form, the LPFs are actually implemented in discrete time form (i.e., digital filters) as the incoming HUMS data are digital. The LPF associated with each data channel is discretized and applied in accordance with the sample rate of the channel. The effect of adding these filters is two-fold. First, it provides improved consistency in the number of steady-state points identified from each engine. Second, it also allows more steady-state points to be identified, particularly at high power regions where the sensor measurements tend to exhibit more variance. Adding the LPFs resulted in approximately a $2.5 \times$ increase in the number of steady-state points identified.

$$
\frac{Y_{\text {filtered }}(s)}{Y_{\text {unfiltered }}(s)}=\frac{\omega_{n}^{2}}{s^{2}+2 \zeta \omega_{n} s+\omega_{n}^{2}}
$$

\section{Thermal Transient Filter}

In investigating the outlier points identified by the steadystate data filter with the low pass filters, it was observed that many of these points were collected immediately after the engine had undergone a substantial power transient. For example, the first data point collected after transitioning from idle power to an intermediate or high power point was often an outlier. These occurrences may have resulted from the fact that the engine had not yet reached a thermal equilibrium; metal temperature thermal heat soak effects are typically slow relative to other engine dynamics. To help address this issue, additional logic was developed and incorporated into the steady-state data filter to ensure that the recorded engine turbine gas temperature (TGT) is in quasi-steady-state for an extended period of time (on the order of minutes) prior to collecting steady-state points. This thermal transient logic is implemented by calculating a lagged version of TGT from the HUMS data with a time constant of $\tau_{\text {therm }}$, and comparing this parameter to the second-order low pass filtered value of TGT. The continuous time formulation of the TGT first order lag is shown in Eq. (6). A discrete version of this equation is implemented within the thermal transient filter.

Figure 3 shows a transient example of TGT (black curve), the corresponding low pass filtered TGT (blue curve), and first order lagged TGT (red curve). ${ }^{1}$ If the absolute difference

\footnotetext{
${ }^{1}$ Due to the proprietary nature of the data, axis scales have been removed from the figures in this document
} 


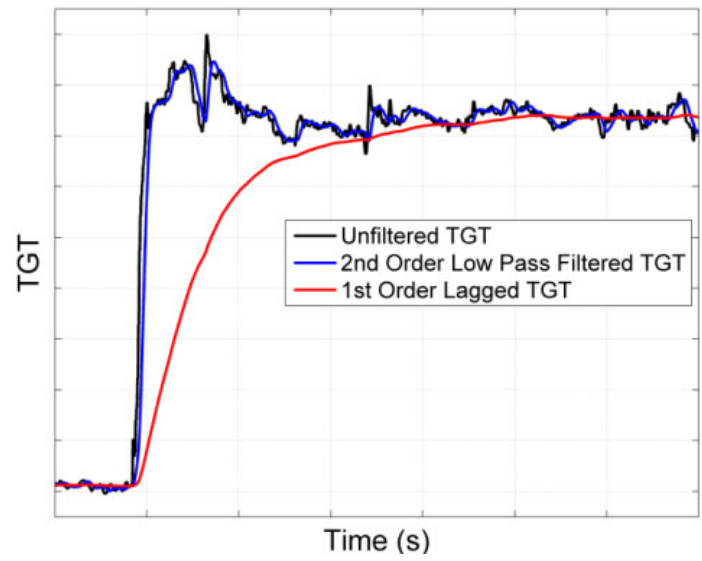

Figure 3.-Comparison of unfiltered, low pass filtered, and lagged TGT during a thermal transient.

between the low pass filtered and lagged versions of TGT is greater than $T_{\text {thermmax }}$ the engine is assumed to be in thermal transient. In this case, the buffer is cleared and the state transition logic enters State 0. Once the absolute difference between these two parameters is less than $T_{\text {thermmax }}$, the logic resumes buffering data. $\tau_{\text {therm }}$ and $T_{\text {thermmax }}$ can be considered tuning parameters. Results will vary as these parameters are adjusted.

$$
\frac{\operatorname{TGT}_{\text {lagged }}(s)}{\operatorname{TGT}_{\text {unfiltered }}(s)}=\frac{1}{\tau_{\text {therm }} s+1}
$$

\section{Operating Regime Recognition Logic}

The steady-state data filter also includes operating regime recognition logic. The purpose of this logic is to ensure that steady-state data are only collected when the engine is operating within a user specified portion of the operating envelope, and to help reduce outlier points. For example, one can include constraints to ensure that data are only collected within a certain altitude, airspeed, power setting, or time range within the flight profile. Additional logic can be included to ensure that steady-state data are not collected while the engine is operating in a mode known to impact engine performance, such as when the anti-ice bleed system is on.

\section{Helicopter Engine Example}

HUMS data sets provided by the U.S. Army were used to develop and evaluate the steady-state data filter. All HUMS data provided were collected from UH-60L aircraft equipped with T700-GE-701C engines. The T700-GE-701C engine serves as the power plant for the latest UH-60L Black Hawk variants and AH-64A/D Apaches (Refs. 8 and 9). This 1800 horsepower-class engine is a modular two-spool design consisting of a gas generator section and a free power turbine. The engine is controlled through the interaction of an Electrical Control Unit and a Hydromechanical Control Unit. These HUMS data sets included data from 15 different vehicle tail numbers (30 engines) encompassing 1688 missions totaling 2813 aircraft flight hours. Also, these data consisted of a select subset of the HUMS parameters available. A list of the 14 HUMS parameters provided, along with their associated sample rates, is shown in Table 1.

\section{TABLE 1.-HUMS PARAMETERS}

\begin{tabular}{|c|c|c|}
\hline $\begin{array}{c}\text { Parameter } \\
\text { name }\end{array}$ & $\begin{array}{l}\text { Sample } \\
\text { rate }\end{array}$ & Definition \\
\hline 1. Time_Stamp & Variable & Time of data sample \\
\hline 2. Baro_Alt & $5 \mathrm{~Hz}$ & Pressure altitude (ft) \\
\hline 3. Anti-Ice 1 & $1 \mathrm{~Hz}$ & Engine 1 anti-ice bleed (on/off) \\
\hline 4. Anti-Ice 2 & $1 \mathrm{~Hz}$ & Engine 2 anti-ice bleed (on/off) \\
\hline 5. KIAS & $5 \mathrm{~Hz}$ & Indicated airspeed (knots) \\
\hline 6. $\mathrm{Ng} 1$ & $5 \mathrm{~Hz}$ & Engine 1 gas generator speed $(\%)$ \\
\hline 7. $\mathrm{Ng} 2$ & $5 \mathrm{~Hz}$ & Engine 2 gas generator speed (\%) \\
\hline 8. Np 1 & $5 \mathrm{~Hz}$ & Engine 1 power turbine speed $(\%)$ \\
\hline 9. $\mathrm{Np} 2$ & $5 \mathrm{~Hz}$ & Engine 2 power turbine speed $(\%)$ \\
\hline 10. OAT & $2 \mathrm{~Hz}$ & Outside air temperature $\left({ }^{\circ} \mathrm{C}\right)$ \\
\hline 11. TGT 1 & $2 \mathrm{~Hz}$ & Engine 1 turbine gas temp $\left({ }^{\circ} \mathrm{C}\right)$ \\
\hline 12. TGT 2 & $2 \mathrm{~Hz}$ & Engine 2 turbine gas temp $\left({ }^{\circ} \mathrm{C}\right)$ \\
\hline 13. Torque 1 & $5 \mathrm{~Hz}$ & Engine 1 torque $(\%)$ \\
\hline 14. Torque 2 & $5 \mathrm{~Hz}$ & Engine 2 torque $(\%)$ \\
\hline
\end{tabular}

Tables 2 through 5 show the various constraints and design parameters applied in setting up the steady-state data filter for the helicopter engine data example. The maximum acceptable standard deviation, $\sigma$, for each parameter, along with the minimum buffer window length, $T_{\text {minbuff, }}$ is shown in Table 2 . All seven of the $\sigma$ constraints and the $T_{\text {minbuff }}$ constraint must be met for an engine to be considered in steady-state. There is a trade-off in the specification of these parameters - smaller $\sigma$ constraints and a larger minimum buffer size will generally result in improved quality (less variance) in the identified steady-state points, although there will be relatively fewer of them, whereas larger $\sigma$ constraints and a smaller minimum buffer size will result in greater variance but more identified points. The values in Table 2 were established manually through trial and error while observing the quality of the identified steady-state data.

The design parameters for the low pass filter and the thermal transient filter are shown in Tables 3 and 4. Similar to the $\sigma$ and $T_{\text {minbuff }}$ constraints, these values were chosen through trial and error while observing the quality of the identified steady-state data. 
TABLE 2.-STEADY-STATE DATA FILTER MAXIMUM ACCEPTABLE STANDARD DEVIATION LEVELS AND MINIMUM BUFFER WINDOW LENGTH

\begin{tabular}{|c|c|}
\hline Parameter & $\begin{array}{c}\text { Maximum } \sigma \\
\text { and minimum buffer length }\end{array}$ \\
\hline Torque $\sigma$ & $0.5 \%$ \\
$\operatorname{Ng} \sigma$ & $0.2^{\circ} \%$ \\
TGT $\sigma$ & $1.5^{\circ} \mathrm{C}$ \\
Np $\sigma$ & $0.2^{\circ} \%$ \\
Baro Altitude $\sigma$ & $30 \mathrm{ft}$ \\
KIAS $\sigma$ & $4 \mathrm{knots}$ \\
OAT $\sigma$ & $1{ }^{\circ} \mathrm{C}$ \\
$T_{\text {minbuff }}$ & $15 \mathrm{~s}$ \\
\hline
\end{tabular}

TABLE 3.-LOW PASS FILTER DESIGN PARAMETERS

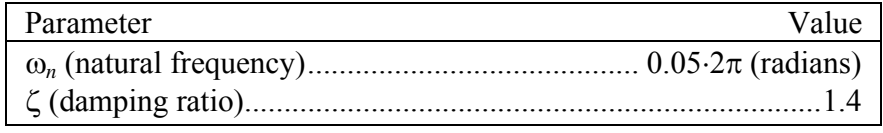

TABLE 4.-THERMAL TRANSIENT FILTER DESIGN PARAMETERS

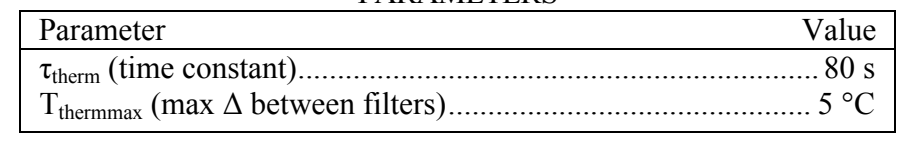

The applied operating regime logic constraints are shown in Table 5. For this example, steady-state points are only collected above 90 percent corrected gas generator speed to avoid engine start-up and idle operating points. Logic is also applied to make sure the engine anti-ice bleed valve is not open, as that will impact engine performance. Additionally, logic is applied to make sure that the aircraft is operating in flight at an indicated airspeed (KIAS) above 40 knots. It was observed that many of the steady-state outlier points were collected at the start of a mission while the aircraft was operating on the ground. While the cause of these outliers is not completely understood, adding the KIAS operating regime constraint helped to alleviate that problem.

TABLE 5.-OPERATING REGIME LOGIC CONSTRAINTS

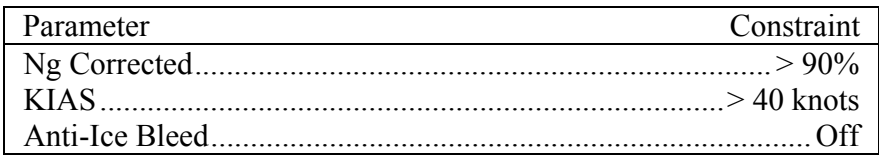

\section{Results}

Figure 4 shows a time history plot of TGT collected from one engine over one flight. This illustrates the highly transient behavior of the data and the challenge in identifying steadystate operating points.

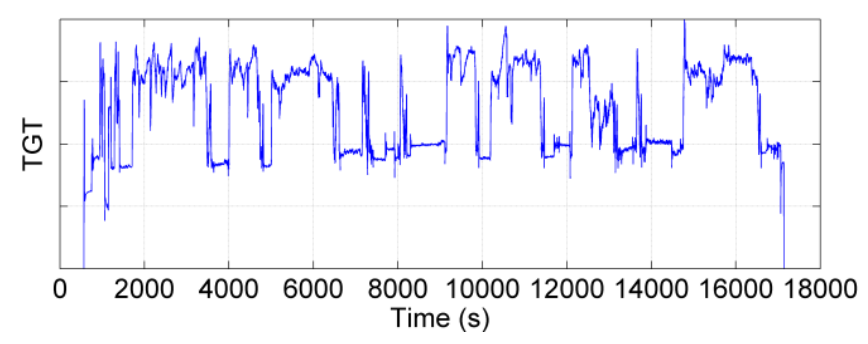

Figure 4.-Measured TGT from one engine over one flight.

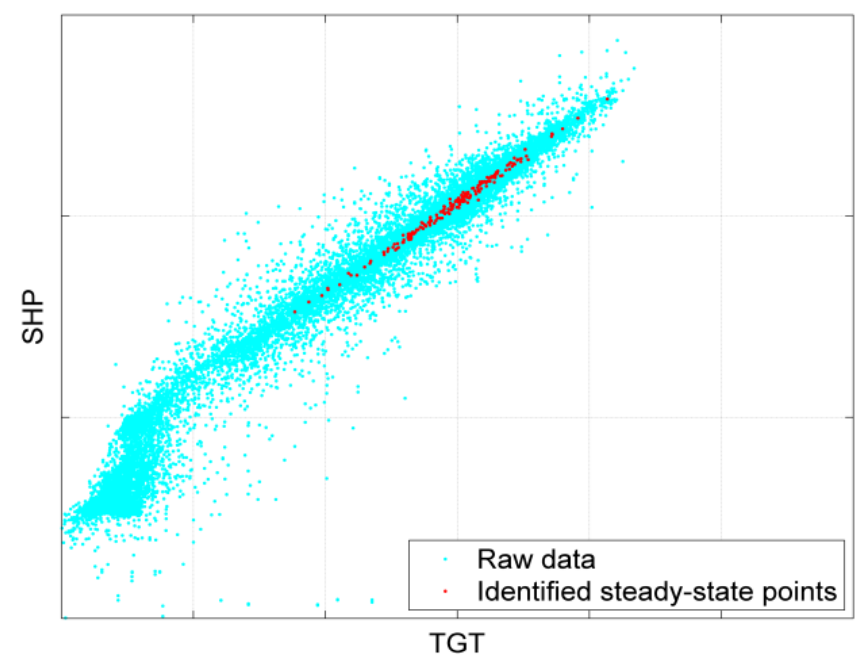

Figure 5.-Comparison of raw and steady-state SHP versus TGT data collected from a single flight.

An example of the steady-state HUMS data from a single flight is shown in Figure 5. Here $\mathrm{SHP}^{2}$ versus TGT data are plotted. Because engine operation is strongly influenced by the ambient operating conditions, corrected parameters (Ref. 10) are shown here and throughout the remainder of the paper to reduce data scatter. In Figure 5, the cyan points represent all of the raw SHP versus TGT data collected during the mission while the red points represent the steady-state points identified by the steady-state data filter. Due to transient operating excursions, a considerable amount of variation is evident in the raw data. The steady-state points represent a tighter clustering around the engine steady-state operating line.

Figure 6 shows a scatter plot of the steady-state data points identified from a single engine over a 5 month period of time. The upper half of the figure shows $\mathrm{Ng}$ versus TGT data and the lower half of the figure shows SHP versus TGT data. The color of each point denotes the time the steady-state point was collected, corresponding to the color bar on the right side of the plots. As a point of reference, the engine steady-state cycle deck response at the corrected operating condition is shown (green curves).

\footnotetext{
${ }^{2}$ Note: Shaft horsepower, SHP, which is proportional to torque times power turbine speed, is not measured directly. It is calculated as: $\mathrm{SHP}=$ Constant $\times$ Torque $\times \mathrm{Np}$
} 
Engine condition monitoring is frequently conducted by comparing engine data to a reference model, e.g., a cycle deck. The difference between the actual engine data and the reference model forms what are known as performance residuals or performance deltas (Ref. 2). Figure 7 shows a scatter plot of the $\Delta \mathrm{Ng}$ and $\Delta \mathrm{SHP}$ performance residuals for the same steady-state engine data shown in Figure 6. At each identified steady-state operating point, a $\Delta \mathrm{Ng}$ and $\Delta \mathrm{SHP}$ residual were generated by referencing the mean $\mathrm{Ng}$ and SHP data against that predicted by the cycle deck when run to the corresponding altitude, airspeed, OAT, and turbine temperature (TGT). For this engine, it can be observed that $\Delta \mathrm{Ng}$ is operating at approximately 1 percent above nominal over the entire TGT operating range. The $\triangle$ SHP residual is shown to vary as a function of TGT. This relationship is due to the lapse rate effects of the T700 engine. Power lapse rate reflects the change in the ratio of actual to rated power with operating condition and deterioration level. The steady-state data examples shown over the remainder of the paper will present residual data.

\section{Results-Benefit of Including the Low Pass Filter (LPF) and the TGT Thermal Transient Filter}

Figure 8 illustrates the benefit of including the low pass filter in the steady-state data filter logic. This figure shows a comparison of the steady-state data points identified with and without applying the LPF. All results are based on a HUMS data set collected from a single aircraft over 45 days. The upper two subplots show the $\triangle \mathrm{SHP}$ versus TGT steady-state data collected without the LPF, while the bottom two subplots show the data collected with the LPF. The inclusion of the LPF significantly increases the number of steady-state points identified. Furthermore, the number of steady-state points identified on each of a helicopter's two engines was found to correlate better when the LPF was applied.

As previously described, the application of the TGT thermal transient filter excludes steady-state data collected immediately after the engine has undergone a significant thermal transient. Figure 9 shows an example of the $\Delta$ SHP versus TGT steady-state data points identified without (top plot) and with (bottom plot) this filter. This example is based upon data collected from one engine over a two month time period. In the top plot there are several outlier points above the main cluster of data. In the bottom plot most of these points have been eliminated. The inclusion of the TGT filter results in a tighter clustering of the data, but it also reduces the overall number of steady-state points identified. A system designer must weigh these trade-offs when deciding whether or not to include the filter, and also when choosing what values to specify for the filter's design parameters.

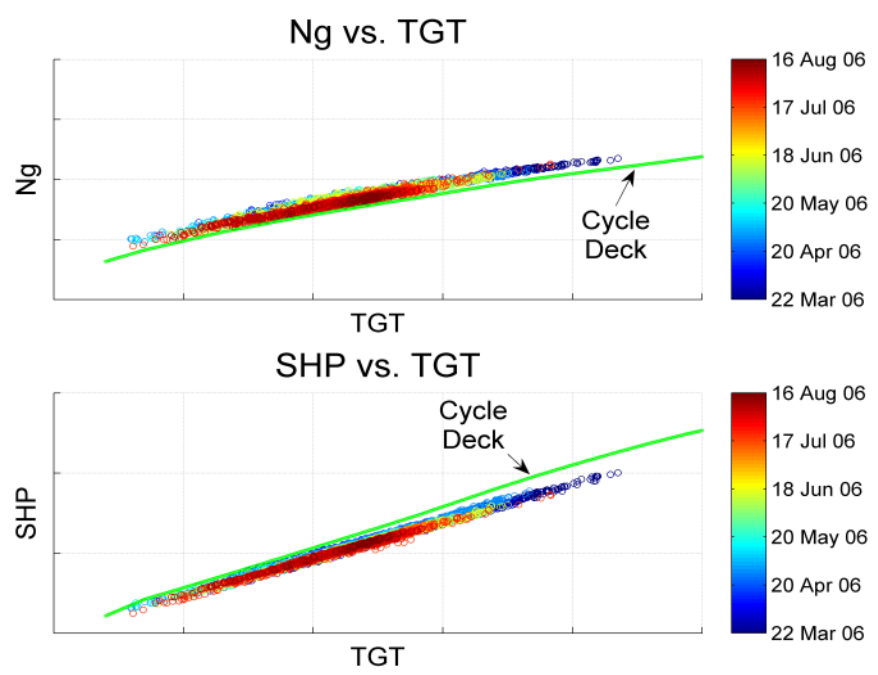

Figure 6.-Example of the steady-state data collected from an individual engine over 5 months.

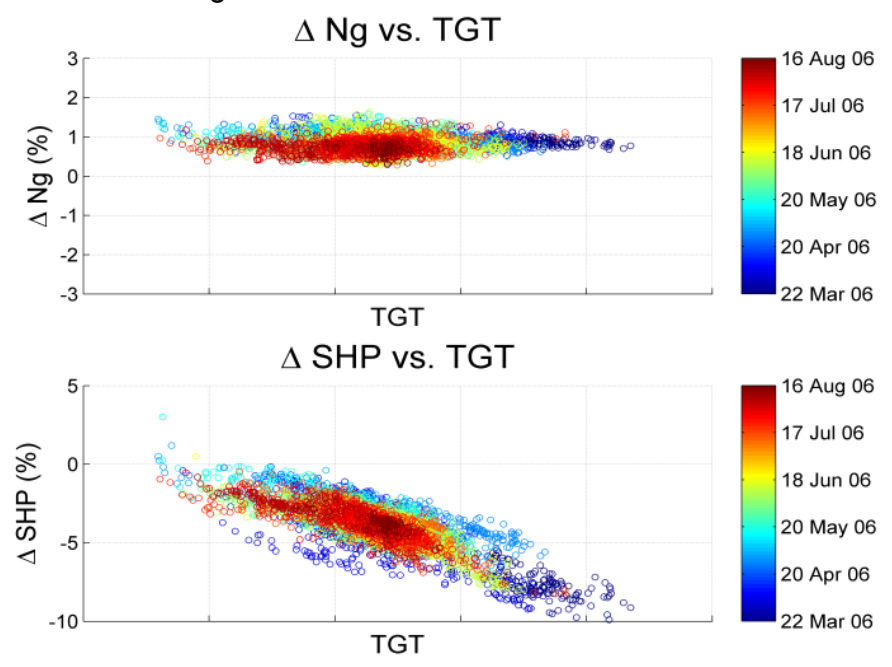

Figure 7.-Example of the steady-state residual data collected from an individual engine over 5 months.
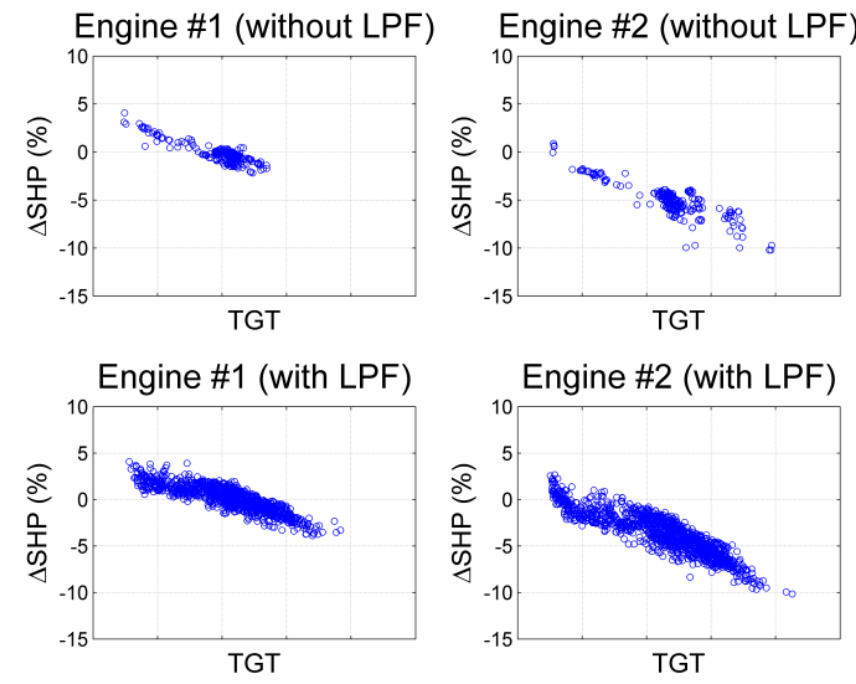

Figure 8.-Example of $\Delta$ SHP versus TGT with and without LPF. 

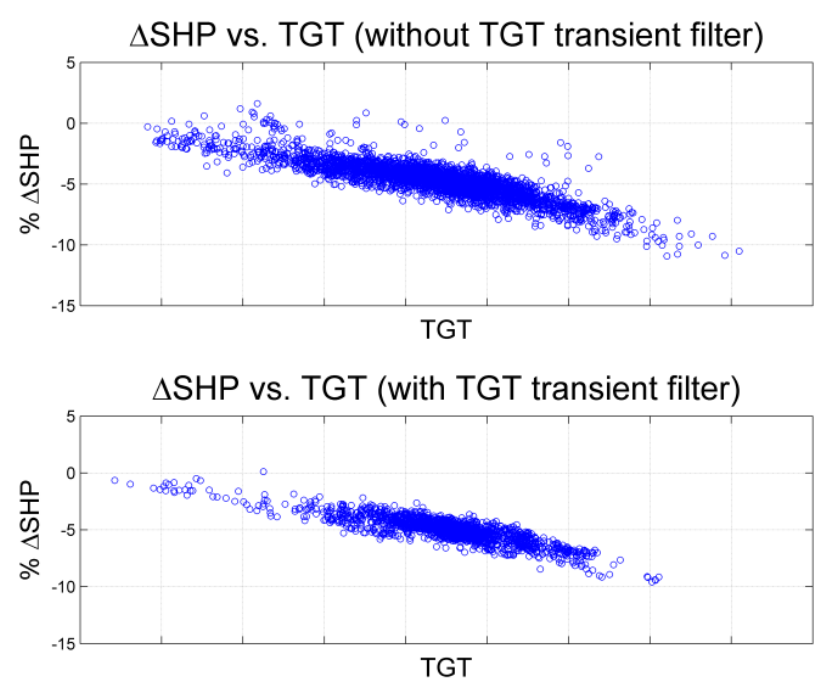

Figure 9.-Example of $\Delta$ SHP versus TGT with and without TGT transient filter.
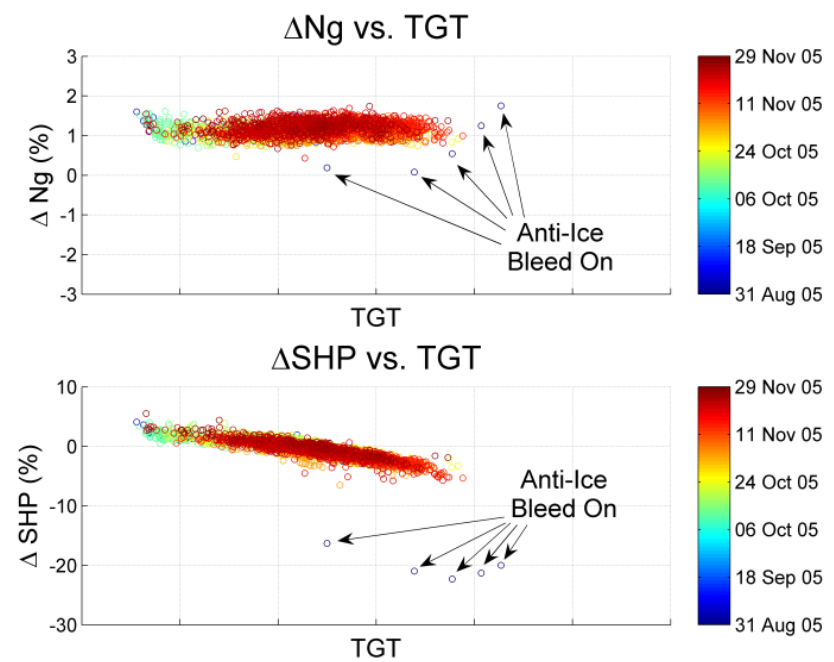

Figure 10.-Example of steady-state points collected with antiice bleed valve open.
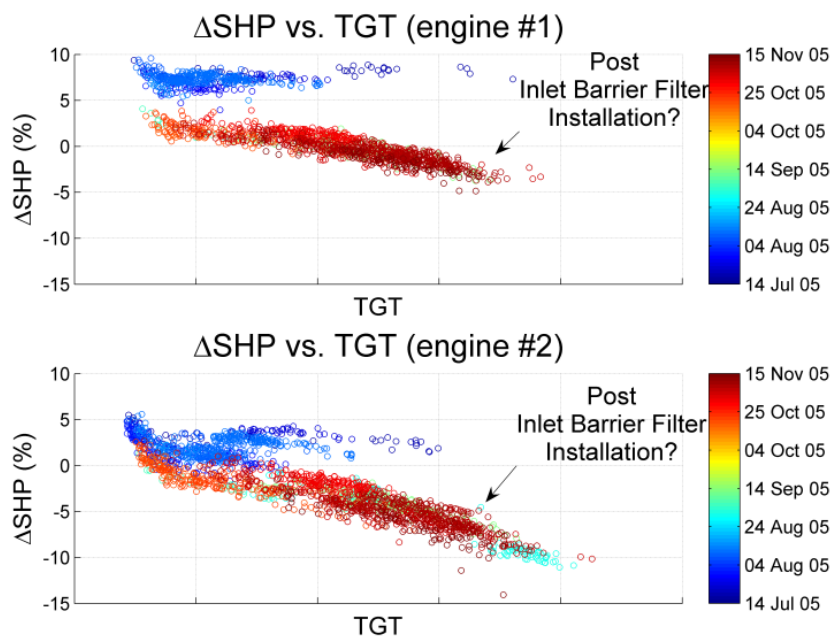

Figure 11.-Example of steady-state data points collected with (postulated) inlet barrier filter installation.

\section{Results-Visualization of Changes in Engine Performance}

In analyzing the HUMS data sets, it was observed that several of the engines exhibited abrupt performance shifts. These events were all discovered through manual analysis-the steady-state data filter does not include any automated diagnostic functionality. Several examples of these events are shown and discussed below to demonstrate how the steady-state data filter outputs could potentially be used for engine condition monitoring purposes if coupled with diagnostic logic.

\section{Anti-Ice Bleed On}

As previously described, the operating regime recognition logic includes a check to make sure that the engine anti-ice bleed valve is not open when steady-state data are collected. To illustrate what could occur if that logic were not included, a HUMS data set was analyzed using the steady-state data filter with the anti-ice bleed valve logic disabled. Figure 10 shows the results of that evaluation. Here five steady-state data point outliers were identified. These five points were collected on a single flight while the anti-ice bleed valve was open. These points are approximately -15 percent $\Delta$ SHP from the other steady-state points collected from the engine. The shift in $\Delta \mathrm{Ng}$ when the bleed valve is open is less apparent. Although this example is not an actual bleed anomaly it illustrates how the steady-state data filter could be used to recognize bleed valve faults.

\section{Installation of Auxiliary Hardware}

Figure 11 shows an example of the steady-state $\triangle \mathrm{SHP}$ versus TGT data collected from two engines installed on the same aircraft over a three month time period. Both engines undergo an abrupt decrease in $\triangle \mathrm{SHP}$ on the same date. Steady-state points collected after this date are denoted by the cyan through red color spectrum. While the authors have no knowledge of the actual cause, it is postulated that this shift was due to the installation of inlet barrier filters on the engines. Like the anti-ice bleed valve example, this is not an actual anomaly. However, it illustrates the potential use of the tool to reveal abrupt performance shifts. It also demonstrates the need to be aware of any maintenance actions or the installation of auxiliary hardware, such as inlet barrier filters, on the engine(s).

\section{Instrumentation Anomalies}

Figure 12 to Figure 14 show three instrumentation anomalies that were discovered in the HUMS data sets. The first example, shown in Figure 12, depicts steady-state data collected from an engine over a three month time period. The figure contains two separate groupings of steady-state data. The initial data (blue points) were collected when a bias was present in the TGT measurement recorded in the HUMS unit. A clearly discernable shift in the data is evident on the flights 

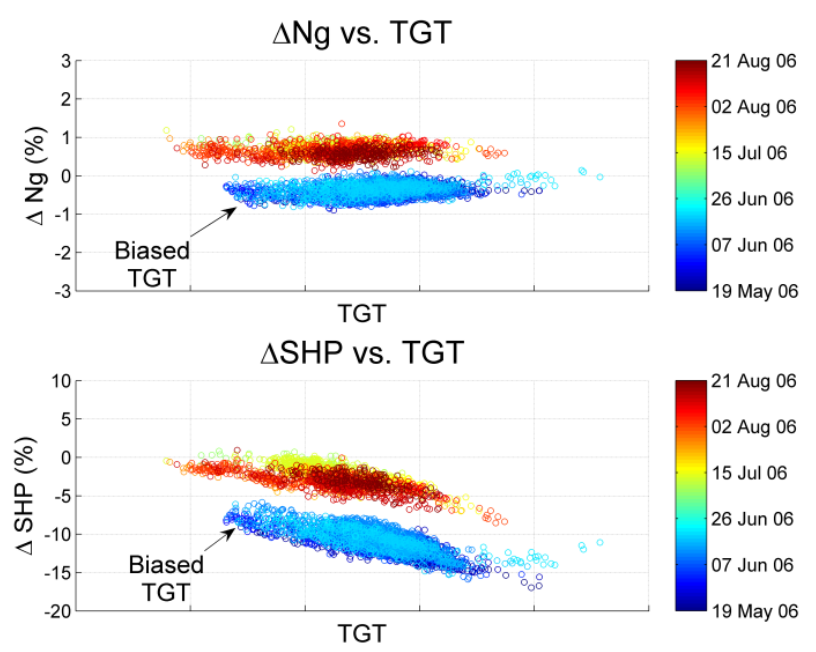

Figure 12.-Example of steady-state data points collected with a TGT instrumentation bias.

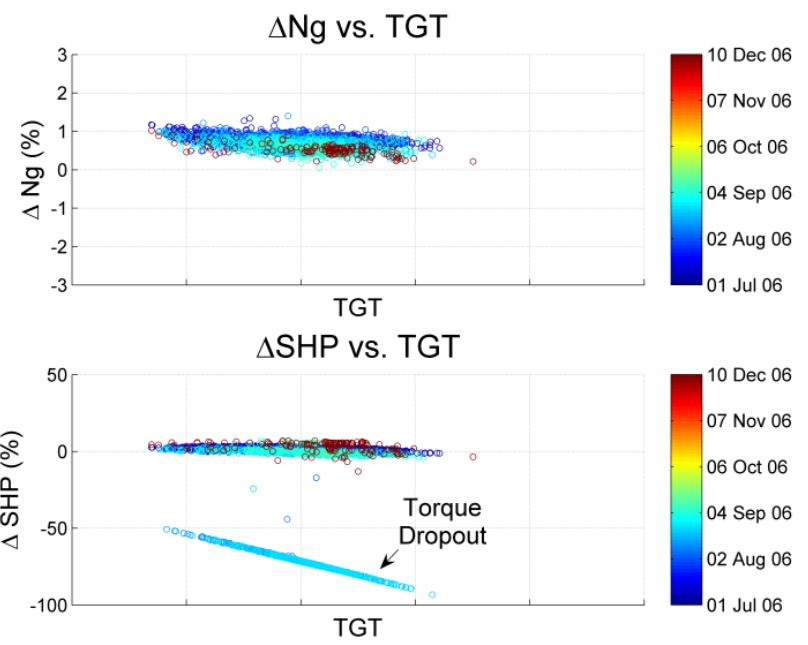

Figure 13.-Example of steady-state data points collected with a torque measurement dropout.

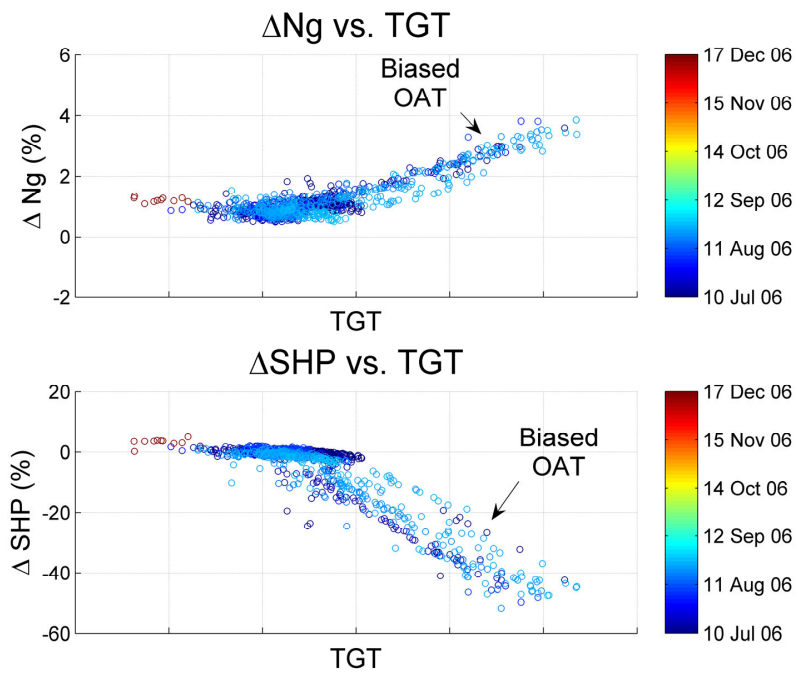

Figure 14.-Example of steady-state data points collected with an OAT instrumentation bias. after this problem was rectified (red points). Since both $\Delta \mathrm{Ng}$ and $\triangle$ SHP are referenced against TGT, this anomaly resulted in a noticeable shift in both plots $(\Delta \mathrm{Ng}$ versus TGT and $\Delta \mathrm{SHP}$ versus TGT).

Figure 13 shows an example of the steady-state data collected when a dropout of the torque measurement occurred. Unlike the previously presented TGT bias example, this instrumentation anomaly was intermittent. At times the torque reading appeared correct, while at other times a full dropout (torque reading of zero) or a partial dropout (incorrect reading greater than 0) occurred. SHP is calculated as a function of the recorded torque and power turbine speed. Therefore the torque dropout instrumentation anomaly is evident in the $\Delta \mathrm{SHP}$ versus TGT plot, but does not affect the $\Delta \mathrm{Ng}$ versus TGT plot as $\mathrm{Ng}$ is sensed directly (i.e., it is not calculated as a function of measured torque).

The final instrumentation anomaly example is shown in Figure 14. This figure shows steady-state data points from an aircraft experiencing intermittent bias in the outside air temperature (OAT) measurement. The recorded aircraft OAT measurement intermittently exhibited a negative bias as large as $80{ }^{\circ} \mathrm{C}$. OAT is used for parameter correction (correction of $\mathrm{Ng}$, SHP, and TGT), as well as input to the cycle deck used to calculate the nominal $\mathrm{Ng}$ and SHP values. Therefore, any bias in OAT will have a pervasive effect on the $\Delta \mathrm{Ng}$ versus TGT and $\triangle$ SHP versus TGT plots. Although data from only one engine are shown, the OAT bias has the same effect on the data collected from each engine installed on the same aircraft.

\section{Discussion}

The development of the steady-state data filter described in this paper was an evolutionary process. The initial version of the architecture only contained the state transition logic, which is completely general and applicable to any dynamic system. Due to the insufficient quantity and quality of the steady-state points identified by the filter, attributed primarily to characteristics of the engines' operation, additional domainspecific functionality was progressively added. This included the low pass filter, the thermal transient filter, and the operating regime recognition logic (see Figure 1). Discussions with T700 domain experts in the U.S. Army proved to be invaluable during this process. These discussions provided insight into the engine operating modes that could impact performance readings, and approaches that could be taken to improve the filter, including those that help to reduce data outliers. Based on the experience with the T700 helicopter engine data, it is expected that similar adaptations would be necessary to extend the technique to other gas turbine engine applications.

In analyzing the HUMS data sets, it was found that instrumentation anomalies and the occurrence of events that impacted engine performance were fairly common. If unaccounted for, these events could negatively impact the performance of an engine monitoring system that relies on the 
identified steady-state data to make engine health assessments. Consequently, additional sensor validation logic should be included within the engine monitoring system in a practical implementation (Refs. 11 and 12). Furthermore, it would be beneficial for such an engine monitoring system to have knowledge of engine maintenance actions that might impact performance readings, including engine overhauls, line maintenance, or installation of auxiliary hardware such as inlet barrier filters. In the case of the automated power assessment logic described in Reference 4, trend monitoring reset logic was included in case the engine performance parameters are observed to undergo an abrupt shift. This allows a more rapid and accurate response to performance changes.

As shown in Tables 1 to 5 , the steady-state data filter incorporates a number of user-defined design parameters. To a large degree the specification of these parameter values is made based on a manual assessment of the data identified by the filter. There are definite trade-off decisions. The designer is typically faced with choosing between quantity (i.e., more points) versus quality (i.e., less variance in the data and fewer outliers). For instance, for a fault detection scheme it would be important to eliminate known outliers to help reduce false alarms.

In the case of the automated power assessment logic described in Reference 4, the objective is to provide a realtime assessment of available power. Therefore, every steadystate point identified was utilized. However, if the data were to be used for other applications, such as ground-based postflight performance trend monitoring, it might be prudent to include logic to limit the number of steady-state points collected. This would be desirable if the cost of telemetering large quantities of data off the aircraft is a concern, or if the end user wants to maintain uniform temporal spacing between the data points collected. Additionally, logic could be added to constrain the filter to collect only a specified number of points each flight. This could be within fixed ranges of engine operating power specified by the user (e.g., ground idle, intermediate power, high power).

\section{Conclusions}

A technique for the automatic detection and archiving of steady-state engine operating points has been developed and demonstrated. Its ability to effectively recognize steady-state segments in transient data has been shown. The initial implementation was completely general and applicable to any dynamical system. In the course of developing the tool, several domain-specific enhancements were incorporated to improve the performance of the steady-state data filter. These enhancements included low pass filtering of the incoming data, logic to avoid collecting data immediately after a major thermal transient, and operating regime recognition logic to constrain the operating point and operating mode where data are collected. The technique has been demonstrated to be effective in revealing engine performance shift events due to the installation of auxiliary hardware and instrumentation anomalies.
The steady-state data filter could be an important part of a diagnostic system for engines that do not have a consistent operating profile, such as those on military vehicles. Its ability to identify and archive steady-state points for use in trend monitoring can have a profound impact on the way propulsion health monitoring is carried out; an example of this impact is the previously reported turboshaft engine power assurance system, which uses this filter. Although designed for real-time on-board implementation, the filter could also serve an important role for post-processing of engine data collected in flight. The storage requirements necessary to archive full flight HUMS data collected from a fleet of aircraft is staggering. The data filter could be used to compress engine flight data into a small number of steady-state performance points collected during each flight. This approach could eliminate the need for long term archiving of the HUMS data, thus greatly reducing data storage requirements.

\section{References}

1. Society of Automotive Engineers E-32, 2005, "A Guide to the Development of a Ground Station for Engine Condition Monitoring," SAE Aerospace Information Report 4175A.

2. Von Karman Institute for Fluid Dynamics, 2003, "Gas Turbine Condition Monitoring and Fault Diagnostics," Lecture Series 200301 .

3. Doel, D., 1994, "TEMPER - A Gas-Path Analysis Tool for Commercial Jet Engines," Journal of Engineering for Gas Turbines and Power, Vol. 116, pp. 82-89.

4. Simon, D.L., Litt, J.S., 2008, "Automated Power Assessment for Helicopter Turboshaft Engines," NASA/TM-2008-215270, American Helicopter Society Forum 64, Montreal, QC, Apr. $29-$ May 1.

5. Pébay, P., 2008, "Formulas for Robust, One-Pass Parallel Computation of Covariances and Arbitrary-Order Statistical Moments," Technical Report SAND2008-6212, Sandia National Laboratories.

6. Chan, T.F., Golub, G.H., LeVeque, R.J., 1979, "Updating Formulae and a Pairwise Algorithm for Computing Sample Variances," Technical Report STAN-CS-79-773, Department of Computer Science, Stanford University.

7. Young, P., 1984, "Recursive Estimation and Time Series Analysis: An Introduction," Springer-Verlag New York, Inc., New York, NY.

8. "Technical Manual, Aviation Unit and Intermediate Maintenance Manual, Engine, Aircraft Turboshaft Models T700-GE-700, T700GE-701, T700-GE-701C, T700-GE-701D," Army TM 1-2840248-23, Headquarters, Departments of the Army and the Air Force, 1 Jun. 1999.

9. GE Aviation website: http://www.geae.com/engines/military /t700/t700-701c.html, accessed Nov. 20, 2009.

10. Volponi, A.J., 1999, "Gas Turbine Parameter Corrections," Journal of Engineering for Gas Turbines and Power, Vol. 121, pp. 613-621.

11. Volponi, A. J., 1994, "Sensor Error Compensation in Engine Performance Diagnostics," ASME Paper 94-GT-58.

12. Healy, T.A., Kerr, L.J., Larkin, L.J., 1998, "Model Based Fuzzy Logic Sensor Fault Accommodation," Journal of Engineering for Gas Turbines and Power, Vol. 120, pp. 533-536. 


\begin{tabular}{|c|c|c|}
\hline \multicolumn{2}{|c|}{ REPORT DOCUMENTATION PAGE } & $\begin{array}{l}\text { Form Approved } \\
\text { OMB No. 0704-0188 }\end{array}$ \\
\hline \multicolumn{3}{|c|}{$\begin{array}{l}\text { The public reporting burden for this collection of information is estimated to average } 1 \text { hour per response, including the time for reviewing instructions, searching existing data sources, gathering and maintaining the } \\
\text { data needed, and completing and reviewing the collection of information. Send comments regarding this burden estimate or any other aspect of this collection of information, including suggestions for reducing this } \\
\text { burden, to Department of Defense, Washington Headquarters Services, Directorate for Information Operations and Reports (0704-0188), } 21215 \text { Jefferson Davis Highway, Suite } 1224 \text {, Arlington, VA } 22222-24302 \text {. } \\
\text { Respondents should be aware that notwithstanding any other provision of law, no person shall be subject to any penalty for failing to comply with a collection of information if it does not display a currently valid OMB } \\
\text { control number. } \\
\text { PLEASE DO NOT RETURN YOUR FORM TO THE ABOVE ADDRESS. }\end{array}$} \\
\hline $\begin{array}{l}\text { 1. REPORT DATE (DD-MM-YYYY) } \\
01-07-2010\end{array}$ & $\begin{array}{l}\text { 2. REPORT TYPE } \\
\text { Technical Memorandum }\end{array}$ & 3. DATES COVERED (From - To) \\
\hline \multirow{3}{*}{\multicolumn{2}{|c|}{$\begin{array}{l}\text { 4. TITLE AND SUBTITLE } \\
\text { A Data Filter for Identifying Steady-State Operating Points in Engine Flight Data for } \\
\text { Condition Monitoring Applications }\end{array}$}} & 5a. CONTRACT NUMBER \\
\hline & & 5b. GRANT NUMBER \\
\hline & & 5c. PROGRAM ELEMENT NUMBER \\
\hline \multirow{3}{*}{\multicolumn{2}{|c|}{$\begin{array}{l}\text { 6. AUTHOR(S) } \\
\text { Simon, Donald, L.; Litt, Jonathan, S. }\end{array}$}} & 5d. PROJECT NUMBER \\
\hline & & 5e. TASK NUMBER \\
\hline & & $\begin{array}{l}\text { 5f. WORK UNIT NUMBER } \\
\text { WBS 645846.02.07.03.12 }\end{array}$ \\
\hline \multicolumn{2}{|c|}{$\begin{array}{l}\text { 7. PERFORMING ORGANIZATION NAME(S) AND ADDRESS(ES) } \\
\text { National Aeronautics and Space Administration } \\
\text { John H. Glenn Research Center at Lewis Field } \\
\text { Cleveland, Ohio 44135-3191 }\end{array}$} & $\begin{array}{l}\text { 8. PERFORMING ORGANIZATION } \\
\text { REPORT NUMBER } \\
\text { E-17295 }\end{array}$ \\
\hline \multirow{2}{*}{\multicolumn{2}{|c|}{$\begin{array}{l}\text { 9. SPONSORING/MONITORING AGENCY NAME(S) AND ADDRESS(ES) } \\
\text { National Aeronautics and Space Administration } \\
\text { Washington, DC 20546-0001 }\end{array}$}} & $\begin{array}{l}\text { 10. SPONSORING/MONITOR'S } \\
\text { ACRONYM(S) } \\
\text { NASA }\end{array}$ \\
\hline & & $\begin{array}{l}\text { 11. SPONSORING/MONITORING } \\
\text { REPORT NUMBER } \\
\text { NASA/TM-2010-216359 }\end{array}$ \\
\hline \multicolumn{3}{|c|}{$\begin{array}{l}\text { 12. DISTRIBUTION/AVAILABILITY STATEMENT } \\
\text { Unclassified-Unlimited } \\
\text { Subject Category: } 07 \\
\text { Available electronically at http://gltrs.grc.nasa.gov } \\
\text { This publication is available from the NASA Center for AeroSpace Information, 443-757-5802 }\end{array}$} \\
\hline
\end{tabular}

\section{SUPPLEMENTARY NOTES}

\section{ABSTRACT}

This paper presents an algorithm that automatically identifies and extracts steady-state engine operating points from engine flight data. It calculates the mean and standard deviation of select parameters contained in the incoming flight data stream. If the standard deviation of the data falls below defined constraints, the engine is assumed to be at a steady-state operating point, and the mean measurement data at that point are archived for subsequent condition monitoring purposes. The fundamental design of the steady-state data filter is completely generic and applicable for any dynamic system. Additional domain-specific logic constraints are applied to reduce data outliers and variance within the collected steady-state data. The filter is designed for on-line real-time processing of streaming data as opposed to post-processing of the data in batch mode. Results of applying the steady-state data filter to recorded helicopter engine flight data are shown, demonstrating its utility for engine condition monitoring applications.

15. SUBJECT TERMS

Systems health monitoring; Gas turbine engines; Fault detection; Statistical analysis

\begin{tabular}{|l|l|l|l|c|l|}
\hline \multicolumn{2}{|l|}{ 16. SECURITY CLASSIFICATION OF: } & $\begin{array}{l}\text { 17. LIMITATION OF } \\
\text { ABSTRACT }\end{array}$ & $\begin{array}{l}\text { 18. NUMBER } \\
\text { OF } \\
\text { PAGES }\end{array}$ & $\begin{array}{l}\text { 19a. NAME OF RESPONSIBLE PERSON } \\
\text { STI Help Desk (email:help@sti.nasa.gov) }\end{array}$ \\
\cline { 1 - 2 } $\begin{array}{l}\text { a. REPORT } \\
\text { U }\end{array}$ & $\begin{array}{l}\text { b. ABSTRACT } \\
\text { U }\end{array}$ & $\begin{array}{l}\text { C. THIS } \\
\text { PAGE }\end{array}$ & UU & 17 & $\begin{array}{l}\text { 19b. TELEPHONE NUMBER (include area code) } \\
\text { U }\end{array}$ \\
\cline { 1 - 2 } & & & \\
\hline
\end{tabular}



